\title{
Fluoride: its role in dentistry ${ }^{\S}$
}

\section{Livia Maria Andaló Tenuta(a) Jaime Aparecido Cury ${ }^{(b)}$}

(a) Assistant Professor; (b) Professor of Biochemistry and Cariology - Piracicaba Dental School, University of Campinas (UNICAMP), Piracicaba, SP, Brazil. §aper presented at the "Promotion of Oral Health in the Public and Private Context" National Symposium, held at the $15^{\text {th }}$ Congress of the Brazilian Association for Oral Health Promotion (ABOPREV), May 27-29, 2010, Brasília, DF, Brazil.

\section{Corresponding author:}

Jaime Aparecido Cury

Av. Limeira, 901

Piracicaba - SP - Brazil

CEP: 13414-903

E-mail: jcury@fop.unicamp.br

Received for publication on Jun 29, 2010 Accepted for publication on Jul 15, 2010
Abstract: In spite of decades of research on fluoride and the recognition of its role as the cornerstone of dental caries reduction in the last fifty years, questions still arise on its use at community, self-applied and professional application levels. Which method of fluoride delivery should be used? How and when should it be used? How can its benefits be maximized and still reduce the risks associated with its use? These are only some of the challenging questions facing us daily. The aim of this paper is to present scientific background to understand the importance of each method of fluoride use considering the current caries epidemiological scenario, and to discuss how individual or combined methods can be used based on the best evidence available.

Descriptors: Fluorides, Topical; Dental Caries; Toothpaste; Water.

\section{Understanding dental caries and the fluoride effect}

Since the 60's, caries has been understood as a multifactorial disease, caused by a complex interplay of bacteria, diet, and the host itself. ${ }^{1}$ This view of the disease was the basis for the proposal of many preventive philosophies still in use nowadays, based on the treatment of the disease itself, and not of the sequelae of the disease (the cavities). Although the concepts brought up by pioneer studies on the multiple factors involved in caries disease changed the paradigm of caries and moved Dentistry to a higher level of quality in patient care, in order to understand how fluoride could interfere with the caries disease, we must leave the prominent "Keyes diagram" behind and move forward to a deeper understanding of the biological and social factors involved in the disease.

Using a broader definition to understand the disease, ${ }^{2,3}$ dental caries can only occur if a necessary factor is present: biofilm accumulation on the teeth. But the presence of biofilm is not sufficient for the disease to develop; fermentable carbohydrates must also be present so that acid can be produced in the restricted environment of the biofilm, inducing mineral loss from the underlying tooth structure. The exposure to sugar can thus be considered a determinant factor in dental caries disease, especially if it occurs at a high frequency (e.g. more than 6 times/day ${ }^{4}$ ). If the sugar is sucrose, bacteria in the biofilm are able to not only produce acids, but also synthesize extracellular polysaccharides - sugar polymers that enhance the biofilm cariogenicity by changing its diffusion and adherence properties. ${ }^{5,6}$

Other determinant factors in the development of the disease are saliva and fluoride. Both have significant, positive effects on the reduction of 
mineral loss, by either clearing out the fermentable substrates and acids or buffering the latter, in the case of saliva, or else enhancing mineral precipitation back on teeth, in the case of fluoride. Fluoride can only exert its effect if it is free, soluble in the aqueous oral environment (biofilm fluid or saliva). ${ }^{7}$ As such, fluoride will physicochemically induce mineral precipitation on the tooth structure in the form of fluorapatite; this can happen while demineralization is occurring within the biofilm milieu (an effect called reduction of demineralization), or after acids have been cleared from the biofilm or the biofilm itself was removed (the so-called enhancement of remineralization). ${ }^{8,9}$ Thus, fluoride deposited on the tooth mineral must be regarded as a consequence of reduced mineral loss occurring in the presence of fluoride, and not the goal of its preventive action. Such concepts as "fluoride strengthening teeth", "increasing the resistance of teeth to acids" and "reducing the acid produced by bacteria", although theoretically reasonable, are no longer accepted as clinically relevant to the reduction of caries associated with fluoride use. ${ }^{7,10}$ In other words, fluoride is not able to affect biofilm accumulation (necessary factor) and the production of acids from its exposure to sugars (determinant factor), but will chemically reduce the mineral loss induced by the combination of these two factors, through the precipitation of a fluoridated mineral on teeth. How to maximize this effect, by using fluoride from different methods of delivery, will be the focus of the next sections in this paper.

Although the factors mentioned so far are sufficient to the understanding of the biological factors involved in the caries disease, others can be discussed. The type of substrate on which the process is happening, either enamel or dentine, from permanent or deciduous teeth, can also determine the clinical outcome. Dentine is more soluble than enamel $^{11}$ due to a higher content of mineral contaminants which increase its solubility (e.g. carbonate), and a less organized crystal structure. With age, tooth roots can be exposed to the oral cavity due to physiological or pathological (i.e. periodontal disease) conditions, and root caries can develop in patients whose enamel caries were under control. In this case, the discussion moves to the strength of the fluoride necessary to control root caries (to be discussed later in this paper). Deciduous enamel also has a higher susceptibility to dissolution than permanent enamel, ${ }^{12}$ and the use of fluoride by young children can be discussed not only in the view of its preventive action, but also with respect to the risk of fluorosis development in teeth being mineralized in early childhood.

Besides the necessary and determinant factors involved, the multifactorial nature of dental caries is also influenced by social factors, which can modify the disease outcome. Access to oral health promotion, not only by stressing the value of adequate diet, oral hygiene habits and access to fluoride, but also considering the relative importance given to teeth by populations of different cultural and economical backgrounds, is a challenge continuously faced by health administrators.

\section{Strengths and limitations of fluoride mechanisms to control caries}

The mechanism by which fluoride controls caries has been clearly elucidated in the last decades of the last century. ${ }^{7}$ Fluoride available in the ionic form in the oral cavity is able to counterbalance the mineral losses caused by acid production in the biofilm, by inducing the precipitation of the less soluble mineral phase fluorapatite in the tooth structure. Perhaps the great effect of fluoride to control caries is based on the concentration needed for it to exert its effect: when fluoride is present at concentrations as low as $1 \mu \mathrm{M}$ (approximately $0.02 \mathrm{ppm} \mathrm{F}$ ), the oral fluids (saliva, plaque fluid) are supersaturated with respect to the mineral phase fluorapatite. Thus, even when available at very low concentrations in the mouth, fluoride can induce the precipitation of minerals on teeth. This effect, occurring every day, results in delayed mineral loss and prolongs the time needed for caries lesions to be clinically observed - or even maintains the mineral loss at subclinical stages for the whole life of an individual.

The local effect of fluoride is also desirable when considering that it is needed where the caries disease is occurring, i.e., the oral cavity. Thus, using fluoride in the right concentration (a very low concentration 
is needed as explained above), at the right place (the oral cavity) and at the right time (available continuously in a mouth where the disease is happening) favors its effect to control caries. The many methods of fluoride delivery that will be discussed here are meant to supply the oral cavity with this ion and thus reduce the progression of lesions.

However, the limitations of the anticaries effect of fluoride need to be considered. Fluoride does not interfere with the factors responsible for the disease, namely biofilm accumulation and sugar use. The antibacterial effect of fluoride in the concentrations remaining in the oral cavity, predominantly below $10 \mathrm{ppm}$, cannot affect bacterial metabolism. ${ }^{10}$ Also, once a great mineral loss has occurred, and the clinical signs are already visible (e.g. a white spot lesion), fluoride is not able to replenish the porous area inside the enamel with minerals, but will help impair the process, resulting in the arrestment of the caries lesion progression. The white spot will eventually have a shiny surface, as a result of surface polishing and remineralization in the presence of fluoride, but the white aspect, from the porous areas underneath, will partially remain. ${ }^{8}$

\section{Methods of fluoride use}

The first mechanism proposed to explain fluoride action was based on its incorporation into the mineral structure, reducing the dissolution of this structure due to the lower solubility of the mineral fluorapatite when compared to hydroxyapatite. This mechanism was later shown to be incorrect, since the overall substitution of fluorapatite in the mineral of teeth did not exceed $10 \%$, and could not be responsible for the tremendous reduction in the caries rate observed in the presence of fluoride. Although more than 30 years have passed since the effect of fluoride was recognized as a result of its presence in a soluble, ionic form in the oral cavity, ${ }^{7}$ the mistaken first interpretation of how fluoride works still makes the adequate use of fluoride methods a challenge. The best example is the classification of the methods of fluoride use as "systemic" or "topic". Not only is this classification wrong, considering that the use of fluoridated water aims to deliver fluoride to the oral cavity ("topical effect"), and not to strengthen teeth that are formed during its use ("systemic effect"), but it also makes it difficult to understand how, when and in which form fluoride should be administered. Hence, it is urgent that we leave the classification of "systemic" and "topical" forms of fluoride use behind, and consider that all methods of using fluoride eventually aim at delivering fluoride to the oral cavity, so that it can exert its effect on caries control. ${ }^{13,14}$ Thus, the different ways of using fluoride should be classified according to the strategy used to deliver fluoride to the oral cavity: community-based, individual, professional or the combinations of these.

\section{Community-based methods of fluoride use}

Of all methods tested so far to deliver fluoride according to a community-based approach, fluoridated water is by far the most successful. Based on more than 50 years of research attesting its effectiveness and safety, ${ }^{15}$ fluoridated water is the best method of delivering fluoride on a population basis.

The mechanism by which fluoridated water controls caries is not different from what has already been explained in this paper. The particularity of this method is that fluoride is ingested, and returns to the oral cavity through saliva secretion, via the salivary glands. The main implication of this mechanism of action is that for fluoridated water to be efficacious, it must be ingested continuously. There is no measurable additional effect of having teeth formed under the exposure to fluoridated water, but only of having teeth continuously bathed by fluoride-enriched saliva. Since the concentration of fluoride needed to control caries is within a micromolar range, a small increase in fluoride concentration in saliva of people living in a fluoridated area (about $0.02 \mathrm{ppm} \mathrm{F}$ ), when compared to those living in a non-fluoridated area (about $0.01 \mathrm{ppm} \mathrm{F}),{ }^{16}$ has a tremendous effect.

Another misinterpretation of the benefits gained by fluoridated water is to think that only by drinking fluoridated water will the benefit be available. In fact, when fluoridated water is used to cook meals, it increases their fluoride concentration, thus making fluoride available by the ingestion of food pre- 
pared with fluoridated water. The benefit of cooking rice and beans with fluoridated water was discussed in a recent paper. ${ }^{17}$ It should also be noted that while rice and beans cooked with fluoridated are being chewed, a 4-fold increase in fluoride concentration in saliva is observed before swallowing (unpublished data); the prolonged effect is achieved by low concentrations returning to the mouth via saliva.

\section{Individual methods of fluoride use}

Among the individual methods of fluoride delivery (fluoride toothpastes and rinses), the use of fluoride toothpastes is by far the most important because it combines the use of fluoride with the mechanical removal of the biofilm. There is unequivocal evidence that fluoride toothpastes are efficient to control caries ${ }^{18}$ and have played an important role in the caries decline observed in both developed ${ }^{19}$ and developing countries. ${ }^{20}$

When fluoride toothpastes are used, a high concentration of fluoride is maintained in the mouth (saliva, biofilm fluid) for some minutes. In saliva, fluoride concentration takes 1 or 2 hours to reach the baseline, pre-brushing values. ${ }^{21,22}$ In the biofilm, increased fluoride values are maintained even 10 hours after brushing when fluoride toothpastes are used on a regular basis. ${ }^{23,24}$

It has recently been shown that the enrichment of remnants of plaque not removed by brushing with fluoride from toothpastes is primarily responsible for its anticaries effect. ${ }^{25}$ This means that brushing with fluoride toothpastes is able to protect not only the cleaned surfaces (from which the biofilm was removed), but also the surfaces the toothbrush did not reach. This idea may explain why brushing with a non-fluoride toothpaste, although effective in controlling periodontal inflammation, is not able to significantly reduce caries; to do this, the toothpaste must have fluoride. ${ }^{26}$ In other words, toothbrushing with fluoride toothpaste controls caries by removing the biofilm from easily accessible surfaces, and by enriching the unremoved remnants of biofilm with fluoride. This has been the basis for the recommended use of fluoride toothpastes aiming at improving oral health. ${ }^{27}$
There has been some debate on the effectiveness of fluoride toothpastes based on their fluoride concentration. Toothpastes containing 1,000$1,500 \mathrm{ppm} F$ (also named conventional fluoride toothpastes) have proven highly effective to control caries, by many high-quality, randomized and controlled studies conducted in the last decades. ${ }^{18}$ Toothpastes with increased fluoride concentration (e.g. 5,000 ppm F) have been launched aiming to control root caries, considering that dentine is more caries-prone than enamel. There is some evidence that these toothpastes are more effective than the conventional ones in such cases, ${ }^{28}$ but a review of the literature on this subject is still lacking.

On the other hand, regarding low fluoride concentration toothpastes (e.g. 500 ppm F), a significant number of studies and systematic reviews of the literature have been published in the last few years. In a systematic review published in 2003, Ammari et al. ${ }^{29}$ concluded that more studies were necessary to address the effect of $500 \mathrm{ppm} F$ toothpastes, and that lower concentrations (e.g. $250 \mathrm{ppm} \mathrm{F}$ ) were clearly not as effective as the conventional toothpastes to control caries. A clinical study published in $2008^{30}$ brought some light to this subject, by demonstrating that low fluoride and conventional toothpastes were equally effective to control caries in caries-inactive children, but low fluoride toothpastes used by caries-active children resulted in an increased number of incipient lesions after one year, while the conventional one could control the appearance of new lesions. This was further explained by a recent study ${ }^{31}$ showing that low $\mathrm{F}$ toothpastes are not able to control caries under a high cariogenic challenge (biofilm accumulation and exposure to sucrose 8 times/ day). The lower fluoride availability in the biofilm fluid and solids, either soon after or 10 to 12 hours after the use of a low fluoride toothpaste, may explain these results. A recent systematic review of the literature ${ }^{32}$ confirmed that the effectiveness of fluoride toothpastes is proven in conventional strength formulations, but not in low fluoride ones.

\section{Professional methods of fluoride use}

Some fluoride products are restricted to use by 
the dental professional; this is the case of high-concentration gels and varnishes, and also of fluoridereleasing dental materials.

When a high-concentration fluoride product, such as a fluoride gel (from 9,000 to $12,300 \mathrm{ppm}$ F) or varnish $(22,500 \mathrm{ppm} \mathrm{F})$, is applied on teeth, in addition to the transient increase in fluoride concentration in the oral cavity, a reaction occurs between the soluble fluoride in the product and the tooth mineral resulting in the precipitation of fluoridated minerals (calcium fluoride-like deposits and fluorapatite). Fluorapatite is incorporated within the crystal lattice, and will not dissolve into the oral cavity. However, the calcium fluoride-like deposits may serve as a fluoride reservoir, slowly dissolving and releasing fluoride into the saliva or to the fluid phase of the biofilm accumulated on the teeth. The fluoride released from the calcium fluoride to the biofilm fluid would act by inhibiting demineralization and enhancing remineralization, and this seems to be the main effect of professional fluoride application. $^{33}$

There is significant evidence showing that preventive programs based on professional fluoride application are effective to control caries in populations, ${ }^{34}$ irrespective of the product used. Thus the design for a preventive program based on professional fluoride application, including reapplication frequency (trimonthly, semi-annually, annually) and risk groups to be included in the program, should be based on the capabilities of the professionals involved and on the amount of resources available.

To supply the oral cavity with a source of slow release of fluoride is also the aim of fluoride-releasing dental materials. Increasing evidence suggests that caries around restorations is not the result of "secondary caries" progressing from carious tissue left under the restoration, but rather of the occurrence of a new lesion adjacent to the previous one. ${ }^{3}$ The use of fluoride-releasing materials could thus control the development of this "new lesion" adjacent to a previous restoration. In fact, biofilms formed on glass ionomer restorations are enriched with fluoride released from them, and the resulting inhibition of demineralization around these restorations has been confirmed. ${ }^{35}$ However, systematic reviews of the literature have failed to confirm the greater benefit of glass ionomers, when compared to composite resin, to reduce caries around restorations. ${ }^{36}$ This may be caused by the use of additional methods of fluoride delivery, which could diminish the effect of one method evaluated alone.

\section{Combination of methods of fluoride use}

The main doubts concerning fluoride use come from the combination of methods of delivery. It can be challenging to decide which combinations should be made regarding either individual or community recommendations. Most of these doubts come from the difficulty in understanding the mechanism of action of each method of fluoride use (which are essentially the same: the mechanism of action of the fluoride ion itself) and how it supplies fluoride to the oral cavity, already discussed in the previous sections.

As a general consideration, both fluoridated water and fluoride toothpaste should be recommended to all individuals. ${ }^{37,38}$ This recommendation is based on the plentiful data supporting their effectiveness to control caries. It can even be considered that the low caries prevalence observed nowadays is the result of the continuous use of these two methods of fluoride delivery by many populations.

Additional methods can be recommended for patients at a high risk for caries. ${ }^{37,38}$ These may include professional fluoride application and the use of fluoride releasing dental materials. It should be noted that there is evidence that the regular use of fluoride toothpaste (i.e. 3 times/day) is able to achieve a level of inhibition of enamel demineralization that cannot be improved if a professional fluoride application is combined. ${ }^{23}$ Although professional application is able to reduce enamel demineralization, when it is associated with regular use of fluoride toothpaste no significant improvement of the effect of both is observed. This result was confirmed by a review of the literature on the combination of methods of fluoride use versus fluoride toothpaste alone. ${ }^{39}$ The same was observed when restorations of glass ionomer and composite resin were tested against the use of non-fluoride or fluoride toothpaste. ${ }^{24}$ Although the 
glass ionomer showed a significant effect in reducing enamel and dentine caries around restorations when a non-fluoride toothpaste was used, a similar effect was observed for the composite resin used with fluoride toothpaste. ${ }^{24,40}$ The concomitant use of the effective fluoride toothpaste may explain why some studies fail to demonstrate the clinical effectiveness of glass ionomers to control caries around restorations. ${ }^{36}$

Taken as a whole, these results suggest that when fluoride toothpaste is being used on a regular basis, no additional method of fluoride use is recommended. However, in such situation caries would be under control. On the other hand, patients with active caries wouldn't be using fluoride toothpaste on a regular basis, and for them there is strong recommendation for using an additional fluoride source (Table 1).

Also, recent data show that, for dentine, the combination of fluoride toothpaste and topical fluoride application can be more effective than the use of either alone. ${ }^{41}$ This should be further studied, but could be additional evidence that the amount of fluoride needed to control dentine caries is higher than that for enamel caries.

\section{Balancing the benefits (caries control) and risks (fluorosis development) of using fluoride from toothpaste}

The important role of fluoride toothpaste to con- trol caries in young children has recently been empirically questioned in view of an expected increase in the prevalence of dental fluorosis in young populations. This is an important issue that cannot be addressed without further discussion of some points.

First of all, balancing the benefits and risks of fluoride use is a continuous challenge. In all countries experiencing caries decline in the last decades, fluoride was (and still is) being used in some way. Thus, it should be accepted that fluoride may be necessary to maintain the low prevalence of caries observed nowadays.

On the other hand, since pioneer studies on water fluoridation have demonstrated its effectiveness and safety, it has also become clear that some degree of fluorosis would be present. ${ }^{42}$ The fluoride concentration to be added to water supplies was then calculated to result in the best anticaries benefit that could be achieved while maintaining fluorosis at low levels and low prevalence. Thus, it should be noted that the history of fluoride use to control caries is linked to the acceptance that it could provoke mild alterations on the enamel being formed during its ingestion.

The use of fluoride from toothpaste by young children, resulting in the ingestion of additional fluoride, is the main focus of the growing paranoia on fluorosis. Although the use of fluoride toothpaste by young children can be considered a risk factor for dental fluorosis, ${ }^{43}$ a recent review of the literature ${ }^{44}$ showed that the evidence pointing to the conclu-

\begin{tabular}{|c|c|c|c|c|c|}
\hline \multirow[b]{2}{*}{$\begin{array}{r}\text { Table } 1 \text { - Recommendations } \\
\text { on fluoride use }\end{array}$} & \\
\hline & Method of delivery & $\begin{array}{l}\text { Community- } \\
\text { based }\end{array}$ & Individual & Professional & Recommendations \\
\hline & Fluoridated water & $x$ & & & $\begin{array}{l}\text { Recommended to all } \\
\text { individuals; no restrictions }\end{array}$ \\
\hline & $\begin{array}{l}\text { Fluoride toothpaste } \\
(1,000-1,500 \text { ppm F) }\end{array}$ & & $x$ & & $\begin{array}{l}\text { Daily use recommended to } \\
\text { all individuals; young children } \\
\text { should use a small amount }\end{array}$ \\
\hline & Fluoride rinses & $0.2 \% \mathrm{NaF}$ & $0.05 \% \mathrm{NaF}$ & & $\begin{array}{l}\text { According to caries risk or } \\
\text { activity, restricted to children } \\
\text { aged } 6 \text { or higher }\end{array}$ \\
\hline & Fluoride gel, varnish & & & $x$ & $\begin{array}{l}\text { According to caries risk or } \\
\text { activity, at the community or } \\
\text { individual levels }\end{array}$ \\
\hline & $\begin{array}{l}\text { Combinations of } \\
\text { methods }\end{array}$ & \multicolumn{4}{|c|}{ According to caries risk or activity, at the community or individual levels } \\
\hline
\end{tabular}


sion that starting the use of fluoride toothpaste in children under 12 months of age may be associated with an increased risk of fluorosis is weak and unreliable, and, even for older children, the evidence is equivocal. Additionally, the recommendation that children under the age of 2-3 years use non-fluoride toothpastes is not supported by any scientific study. From many papers on fluoride mechanisms (cited throughout this paper), it is clear that the anticaries effect is completely lost by the use of non-fluoride toothpaste, and the use of low-fluoride formulations is also subject to criticism, as previously discussed. Moreover, there is not a single study showing that this recommendation will keep children free of fluorosis, or even reduce its risk, considering that other sources of fluoride are available.

The best recommendation on the use of fluoride toothpastes by young children, considering the balance of benefits and risks, is that a small amount of dentifrice should be used. For example, by recommending the use of $0.3 \mathrm{~g}$ of toothpaste per brushing (similar to the size of a pea), the amount of fluoride ingested would still fall within the safe limit considering fluorosis risk involving aesthetic issues..$^{45}$ Calculations on the risks and benefits of fluoride toothpaste use by young Australian children showed that the use of a high amount of toothpaste and the habit of eating or licking the toothpaste resulted in an increased risk of fluorosis, without a significant improvement in anticaries benefits. ${ }^{46}$ In fact, since the anticaries effect of fluoride is concentration-dependent (the concentration of free fluoride in the

\section{References}

1. Keyes PH. The infectious and transmissible nature of experimental dental caries. Arch Oral Biol. 1960 Mar;1:304-320.

2. Fejerskov O, Manji F. Risk assessment in dental caries. In: Bader JD, editor. Risk assessment in dentistry. Chapel Hill: University of North Carolina Dental Ecology; 1990. p. 215 7.

3. Kidd EAM, Fejerskov O. What constitutes dental caries? Histopathology of carious enamel and dentin related to the action of cariogenic biofilms. J Dent Res. 2004;83 Special No C): C35-C8.

4. Ccahuana-Vásquez RA, Vale GC, Tenuta LMA, Del Bel Cury AA, Vale GC, Cury JA. Effect of frequency of sucrose exposure mouth), and the fluorosis risk is dose-dependent (the dose of fluoride circulating in the blood according to the child's weight), a reduction in the amount of toothpaste used by young children would reduce the risk of dental fluorosis without significantly affecting its anticaries benefit. ${ }^{47}$ It is thus a recommendation that can be made for all children, irrespective of their social or caries-risk status.

Additionally, studies have shown that the level of fluorosis caused by the association of fluoridated water and fluoride toothpaste is very mild, and a recent review of the aesthetic perceptions of dental fluorosis and the associated oral health-related quality of life ${ }^{48}$ showed that mild fluorosis may even be associated with an improved perception of oral health, probably due to the lower prevalence of caries in such populations.

\section{Conclusions}

1. Fluoride is still considered the best strategy to control caries at either the community or individual levels.

2. Water fluoridation and fluoride dentifrice should be recommended for all individuals.

3. Fluoride rinse, professional fluoride application and fluoride-releasing dental materials may be considered complementary methods of fluoride delivery.

4. Fluoride may be used to control caries with efficiency and safety regarding general health or dental side-effects such as fluorosis.

on dental biofilm composition and enamel demineralization in the presence of fluoride. Caries Res. 2007;41(1):9-15.

5. Dibdin GH, Shellis RP. Physical and biochemical studies of Streptococcus mutans sediments suggest new factors linking the cariogenicity of plaque with its extracellular polysaccharide content. J Dent Res. 1988 Jun;67(6): 890-5.

6. van Houte J, Russo J, Prostak KS. Increased $\mathrm{pH}$ lowering ability of Streptococcus mutans cell masses associated with extracellular glucan-rich matrix material and the mechanisms involved. J Dent Res. 1989 Mar;68(3): 451-9.

7. Proceedings of a Joint IADR/ORCA International Symposium on Fluorides: Mechanisms of action and recommendations 
for use, March 21-24, 1989, Callaway Gardens Conference Center, Pine Mountain, Georgia. J Dent Res. 1990 Feb;69: Special Issue.

8. Cury JA, Tenuta LMA. Enamel remineralization: controlling the caries disease or treating the early caries lesions? Braz Oral Res. 2009; 23 Suppl 1:23-30.

9. Cury JA, Tenuta LM. How to maintain a cariostatic fluoride concentration in the oral environment. Adv Dent Res. 2008 Jul $1 ; 20(1): 13-16$.

10. Emilson CG. Potential efficacy of chlorhexidine against mutans streptococci and human dental caries. J Dent Res. 1994;73:682-91.

11. Hoppenbrouwers PM, Driessens FC, Borggreven JM. The vulnerability of unexposed human dental roots to demineralization. J Dent Res. 1986 Jul; 65(7):955-8.

12. Sønju Clasen AB, Ogaard B, Duschner H, Ruben J, Arends J, Sönju T. Caries development in fluoridated and non-fluoridated deciduous and permanent enamel in situ examined by microradiography and confocal laser scanning microscopy. Adv Dent Res. 1997;11(4):442-7.

13. Ellwood RP, Fejerskov O, Cury JA, Clarkson B. Fluoride in caries control. In: Fejerskov O, Kidd E, editors. Dental caries: The disease and its clinical management. $2^{\text {nd }}$ ed. Oxford: Blackwell \& Munksgaard; 2008. p. 287-323.

14. Tenuta LMA, Cury JA. Fluoreto: da ciência à prática clínica. In: Sada Assed, organizador. Odontopediatria: bases científicas para a prática clínica. $1^{\text {a }}$ ed. São Paulo: Artes Médicas; 2005. Capítulo 4; p. 113-52.

15. McDonagh MS, Whiting PF, Wilson PM, Sutton AJ, Chestnutt I, Cooper J, Misso K, Bradley M, Treasure E, Kleijnen J. Systematic review of water fluoridation. BMJ. 2000 Oct 7;321(7265):855-9.

16. Oliveby A, Twetman S, Ekstrand J. Diurnal fluoride concentration in whole saliva in children living in a high- and a low-fluoride area. Caries Res. 1990;24(1):44-7.

17. Casarin RC, Fernandes DR, Lima-Arsati YB, Cury JA. Fluoride concentrations in typical Brazilian foods and in infant foods. Rev Saude Publica. 2007;41(4):549-56.

18. Marinho VCC, Higgins JPT, Logan S, Sheiham A. Fluoride toothpastes for preventing dental caries in children and adolescents. Cochrane Database Syst Rev. 2003, Issue 1. Art. No: CD002278.

19. Bratthall D, Hansel-Petersson G, Sundberg H. Reasons for the caries decline: what do the experts believe? Eur J Oral Sci. 1996 Aug;104(4(Pt 2)):416-22.

20. Cury JA, Tenuta LM, Ribeiro CC, Paes Leme AF. The importance of fluoride dentifrices to the current dental caries prevalence in Brazil. Braz Dent J. 2004;15(3):167-74.

21. Serra MC, Cury JA. Saliva fluoride kinetics following the use of a fluoride dentifrice and a fluoride rinse. Rev Assoc Paul Cir Dent. 1992;46(5):875-8. In Portuguese.
22. Zamataro CB, Tenuta LM, Cury JA. Low-fluoride dentifrice and the effect of post-brushing rinsing on fluoride availability in saliva. Eur Arch Paediatr Dent. 2008 Jun;9(2):90-3.

23. Paes Leme AF, Dalcico R, Tabchoury CP, Del Bel Cury AA, Rosalen PL, Cury JA. In situ effect of frequent sucrose exposure on enamel demineralization and on plaque composition after APF application and F dentifrice use. J Dent Res. 2004 Jan;83(1):71-75.

24. Cenci MS, Tenuta LM, Pereira-Cenci T, Del Bel Cury AA, ten Cate JM, Cury JA. Effect of microleakage and fluoride on enamel-dentine demineralization around restorations. Caries Res. 2008;42(5):369-379.

25. Tenuta LM, Zamataro CB, Del Bel Cury AA, Tabchoury CP, Cury JA. Mechanism of fluoride dentifrice effect on enamel demineralization. Caries Res. 2009;43(4):278-285.

26. Scheie AA. Dentifrices in the control of dental caries. In: Embery G, Rölla G, editors. Clinical and biological aspects of dentifrices. Oxford: Oxford University Press; 1992. Chapter 5; p. 29-39.

27. Kay E, Locker D. A systematic review of the effectiveness of health promotion aimed at improving oral health. Community Dent Health. 1998;15(3):132-44.

28. Baysan A, Lynch E, Ellwood R, Davies R, Petersson L, Borsboom P. Reversal of primary root caries using dentifrices containing 5,000 and 1,100 ppm fluoride. Caries Res. 2001 JanFeb;35(1):41-6.

29. Ammari AB, Bloch-Zupan A, Ashley PF. Systematic review of studies comparing the anti-caries efficacy of children's toothpaste containing $600 \mathrm{ppm}$ of fluoride or less with high fluoride toothpastes of 1000 ppm or above. Caries Res. 2003 Mar-Apr;37(2):85-92.

30. Lima TJ, Ribeiro CCC, Tenuta LMA, Cury JA. Low-fluoride dentifrice and caries lesions control in children with different caries experience: a randomized clinical trial. Caries Res 2008;42(1):46-50.

31. Cury JA, do Amaral RC, Tenuta LMA, Del Bel Cury AA, Tabchoury CPM. Low-fluoride toothpaste and deciduous enamel demineralization under biofilm accumulation and sucrose exposure. Eur J Oral Sci. 2010 Aug;118(4):370-375.

32. Walsh T, Worthington HV, Glenny AM, Appelbe P, Marinho VC, Shi X. Fluoride toothpastes of different concentrations for preventing dental caries in children and adolescents. Cochrane Database Syst Rev. 2010 Jan 20;(1):CD007868.

33. Tenuta LM, Cerezetti RV, Del Bel Cury AA, Tabchoury CP, Cury JA. Fluoride release from $\mathrm{CaF}_{2}$ and enamel demineralization. J Dent Res. 2008 Nov;87(11):1032-1036.

34. Marinho VC, Higgins JP, Logan S, Sheiham A. Topical fluoride (toothpastes, mouthrinses, gels or varnishes) for preventing dental caries in children and adolescents. Cochrane Database Syst Rev. 2003;(4):CD002782.

35. Benelli EM, Serra MC, Rodrigues AL Jr, Cury JA. In situ anticariogenic potential of glass ionomer cement. Caries Res. $1993 ; 27(4): 280-284$ 
36. Randall RC, Wilson NH. Glass-ionomer restoratives: a systematic review of a secondary caries treatment effect. J Dent Res. 1999 Feb;78(2):628-637.

37. Tenuta LMA, Cury JA. Fluoreto na prática de promoção de saúde individual e coletiva. Rio de Janeiro: ABOPREV, 2005. Cadernos da ABOPREV IV.

38. Brasil. Ministério da Saúde. Guia de recomendações para o uso de fluoretos no Brasil. Brasília: Ministério da Saúde; 2009. 53 p.

39. Marinho VC, Higgins JP, Sheiham A, Logan S. Combinations of topical fluoride (toothpastes, mouthrinses, gels, varnishes) versus single topical fluoride for preventing dental caries in children and adolescents. Cochrane Database Syst Rev. 2007;(1):CD002781.

40. Hara AT, Turssi CP, Ando M, González-Cabezas C, Zero DT, Rodrigues AL Jr, Serra MC, Cury JA. Influence of fluoridereleasing restorative material on root dentine secondary caries in situ. Caries Res 2006;40(5):435-439.

41. Vale GC, Tabchoury CPM, Del Bel Cury AA, Tenuta LMA, ten Cate JM, Cury JA. APF application and f-dentifrice use on root dentine demineralization. J Dent Res. 2010. Accepted.
42. Fejerskov O, Manji F, Baelum V. The nature and mechanisms of dental fluorosis in man. J Dent Res 1990;69(Special Issue):692-700.

43. Mascarenhas AK. Risk factors for dental fluorosis: a review of the recent literature. Pediatr Dent. 2000 Jul-Aug;22(4):26977.

44. Wong MC, Glenny AM, Tsang BW, Lo EC, Worthington HV, Marinho VC. Topical fluoride as a cause of dental fluorosis in children. Cochrane Database Syst Rev. 2010 Jan 20;(1): CD007693.

45. Paiva SM, Lima YB, Cury JA. Fluoride intake by Brazilian children from two communities with fluoridated water. Community Dent Oral Epidemiol. 2003;31(3):184-91.

46. Do LG, Spencer AJ. Risk-benefit balance in the use of fluoride among young children. J Dent Res. 2007 Aug;86(8):723-38.

47. Ellwood RP, Cury JA. How much toothpaste should a child under the age of 6 years use? Eur Arch Paediatr Dent. 2009 Sep;10(3):168-74.

48. Chankanka O, Levy SM, Warren JJ, Chalmers JM. A literature review of aesthetic perceptions of dental fluorosis and relationships with psychosocial aspects/oral health-related quality of life. Community Dent Oral Epidemiol. 2010 Apr;38(2):97-109. 